\title{
Reliability and Validity of the Korean Young Schema Questionnaire-Short Form-3 in Medical Students
}

\author{
Seung Jae Lee', Young Hee Choi ${ }^{2}$, Hyo Deog Rim¹, Seung Hee Won', and Dong-Woo Lee ${ }^{3 凶}$ \\ ${ }^{1}$ Department of Psychiatry, Kyungpook National University School of Medicine, Daegu, Republic of Korea \\ ${ }^{2}$ Metta Institute, Seoul, Republic of Korea \\ ${ }^{3}$ Department of Psychiatry, Sanggye Paik Hospital, College of Medicine, Inje University, Seoul, Republic of Korea
}

Objective The Young Schema Questionnaire (YSQ) is a self-report measure of early maladaptive schemas and is currently in its third revision; it is available in both long (YSQ-L3) and short (YSQ-S3) forms. The goal of this study was to develop a Korean version of the YSQS3 and establish its psychometric properties in a Korean sample.

Methods A total of 542 graduate medical students completed the Korean version of the YSQ-S3 and several other psychological scales. A subsample of 308 subjects completed the Korean YSQ-S3 both before and after a 2-year test-retest interval. Correlation, regression, and confirmatory factor analyses were performed on the data.

Results The internal consistency of the 90-item Korean YSQ-S3 was 0.97 and that of each schema was acceptable, with Cronbach's alphas ranging from 0.59 to 0.90 . The test-retest reliability ranged from 0.46 to 0.65 . Every schema showed robust positive correlations with most psychological measures. The confirmatory factor analysis for the 18-factor structure originally proposed by Young, Klosko, and Weishaar (2003) showed that most goodness-of-fit statistics were indicative of a satisfactory fit.

Conclusion These findings support the reliability and validity of the Korean version of the YSQ-S3.

Psychiatry Investig 2015;12(3):295-304

Key Words Young schema questionnaire, Short form, Reliability, Validity, Schema.

\section{INTRODUCTION}

Schema theory and therapy, developed by Jeffrey Young, ${ }^{1}$ is an integrative model of psychotherapy for patients with severe, chronic psychological problems who have been considered difficult to treat. Central to the schema model is the notion of early maladaptive schemas (EMSs), defined as broad, pervasive emotional and cognitive patterns that begin early in development and repeat throughout life. ${ }^{2}$ In the meanwhile, schema-related coping styles, as a response to the EMS, develop and often end up rather reinforcing and perpetuating the EMS. ${ }^{1,2}$ The goal of schema therapy is to help patients to understand the origin of their EMS, to identify and stop using maladaptive coping styles, and to build healthy schemas typically

Received: May 29, 2014 Revised: September 12, 2014

Accepted: November 5, 2014 Available online: July 6, 2015

$\triangle$ Correspondence: Dong-Woo Lee, MD, PhD

Department of Psychiatry, Sanggye Paik Hospital, College of Medicine, Inje University, 1342 Dongil-ro, Nowon-gu, Seoul 139-707, Republic of Korea Tel: +82-2-950-1083, Fax: +82-2-950-1082, E-mail: dwlee@paik.ac.kr

(c) This is an Open Access article distributed under the terms of the Creative Commons Attribution Non-Commercial License (http://creativecommons.org/licenses/by$\mathrm{nc} / 3.0$ ) which permits unrestricted non-commercial use, distribution, and reproduction in any medium, provided the original work is properly cited. using limited parenting, imagery, and schema flashcard or diaries. ${ }^{1,2}$ There is a growing literature of outcome studies for patients with borderline personality disorder (BPD) and other chronic Axis I disorders. ${ }^{3-6}$ In a comprehensive review on its effectiveness for BPD patients, schema therapy showed beneficial effects on many facets of BPD psychopathology in both individual and group settings and compared to treatment as usual and other specialized BPD treatment. ${ }^{6}$

To date, Young et al. ${ }^{2}$ have identified 18 different EMSs, each with its own proposed origin and long-term impact. The 18 EMSs are grouped into five more general categories, known as schema domains, which bring together the EMSs that tend to develop together. The EMSs are assessed using the self-report Young Schema Questionnaire (YSQ) ${ }^{7,8}$ Each item in the questionnaire is a statement based on a maladaptive belief as defined by schema theory. Respondents are asked to rate the degree to which they agree with the statements on a six-point Likert scale (1-6). A mean score is calculated for each EMS, with higher scores representing a stronger endorsement of the EMS in question. Since the original long from of the YSQ was introduced in $1990,{ }^{7,8}$ the YSQ has evolved as schema theory has 
continued to develop, and it is currently in its third revision, which is available in both long (YSQ-L3) ${ }^{9}$ and short (YSQ-S3) ${ }^{10}$ forms. Previous psychometric studies reported that the instrument had high internal consistency ${ }^{11-13}$ and adequate test-retest reliability. ${ }^{13,14}$ Studies that tested the concurrent validity of the instrument demonstrated significant correlations with psychological symptoms, ${ }^{15}$ cognitive structures,${ }^{16}$ and attachment styles. ${ }^{17}$ Moreover, discriminant analysis also supported construct validity of the questionnaire. ${ }^{13,1,1,18}$ In sum, both the long and short version of the YSQ-S3 have demonstrated strong internal consistency, reliability, and validity and can be used with generally accurate results in both clinical and non-clinical setting. ${ }^{19}$

In terms of Korean translation, Cho initially developed the Korean version of the 205-item YSQ-L1 among 833 college students. ${ }^{20}$ Sixteen factors were extracted from factor analysis, and 15 of these corresponded exactly with 15 of the 16 EMSs originally proposed by Young et al. ${ }^{7}$ Consistent with previous studies, ${ }^{12,13}$ only the social undesirability schema, which was finally deleted in a later version of the YSQ, was not identified by this Korean version. A higher-order factor analysis indicated that the 16 factors were reorganized into two higher-order factors, namely the vulnerable self and the inflated self.

The Korean version of the 75-item YSQ-S2 was also validated among 833 undergraduate students. ${ }^{11}$ This study demonstrated that the 13-factor YSQ-S2 has good psychometric properties and reliability. That is, of the original 15 EMSs, the subjugation and the dependence/incompetence schemas were not identified as separate factors. It is of note that this study was conducted with Australian undergraduate students at the same time and showed a similar factor structure and internal reliability in the South Korean as well as Australian groups.

Given that the YSQ-S3 was developed in 2005, an updated Korean version of the YSQ-S2 is needed. The necessity of updating the YSQ-S2 is mainly because three schemas, the approval seeking/recognition seeking, the negativity/pessimism, and the punitiveness were added to the YSQ-S3. First, three additional schemas addressed by 15 items need to be validated because this addition could affect the psychometric properties of this instrument. Second, the use of the YSQ-S2 is also outdated in the context of contemporary schema-related research. As three schemas have been added, the structure of schema domains has also been changed. Thus, there is a limitation to compare data between two versions directly. Third, the use of the YSQ-S3 would let clinicians understand patients better with a new 18 set of schemas in a clinical setting. Therefore, the present study aimed to investigate the psychometric properties of a Korean version of the YSQ-S3, which we translated independently from the earlier version.

\section{METHODS}

\section{Participants}

The graduate medical students at the Kyungpook National University School of Medicine participated in this study and completed assessments during their first and third year of medical school from 2009 to 2013. Subjects with previous or current history of psychiatric or neurological diagnoses, or severe medical illness, were excluded. Students who scored above 23 on the Beck Depression Inventory (BDI) in their initial assessment were also excluded. In accordance with the exclusion criteria and/or the data with any missing values, 15 were ruled out. In the final analysis, the sample consisted of 542 graduate students [307 men and 235 women; mean age $(\mathrm{SD})=25.2(2.3)$, range $=21-36$ years]. A subsample of 308 subjects completed the Korean YSQS3 both before and after a 2-year test-retest interval. All participants provided written informed consent after the study had been fully explained. We used data drawn from the mental health assessment for graduate school students, an annual study conducted with the approval of the Ethics Committee of the Kyungpook National University School of Medicine.

\section{Measures}

Young Schema Questionnaire-Short form version 3 (YSQ-S3)

EMSs were assessed with the short form of the Young Schema Questionnaire, version 3 (YSQ-S3), which contains 90 items and assesses 18 EMSs. ${ }^{10}$ Each item is rated on a six-point Likert scale. Higher scores are indicative of stronger endorsements of dysfunctional beliefs. The 18 subscales are grouped into five broad categories, referred to as schema domains: the disconnection and rejection domain consists of abandonment/instability, mistrust/abuse, emotional deprivation, defectiveness/incompetence, and social isolation/alienation; the impaired performance and autonomy domain consists of dependence/incompetence, vulnerability to harm or illness, enmeshment/undeveloped self, and failure; the impaired limits domain consists of entitlement/grandiosity and insufficient self-control/self-discipline; the other-directedness domain consists of subjugation, self-sacrifice, and approval-seeking/recognition-seeking, and the overvigilance and inhibition domain consists of negativity/pessimism, emotional inhibition, and unrelenting standards/hypercriticalness.

The previous version of the YSQ-S2 contained 75 items and was composed of the five highest-loading items for each schema, as determined by factor analysis. ${ }^{13}$ The Korean version of the YSQ-S2 has good psychometric properties and internal reliability $(\alpha=0.94){ }^{11}$ An additional 15 items addressing three new schemas (approval seeking/recognition seeking, negativity/pessimism, and punitiveness) were included in the current YSQ-S3.

With the permission of the authors, the YSQ-S3 was trans- 
lated into Korean by an experienced psychiatrist and a clinical psychologist. It was then back-translated by a bilingual individual, and modifications were made. The final version was approved by the two original translators.

\section{Symptom Checklist-90, revised version}

The Symptom Checklist-90 (SCL-90-R) is a well-validated self-report questionnaire assessing a broad range of psychological problems and symptoms of psychopathology. ${ }^{21} \mathrm{Re}-$ spondents rate 90 items on a five-point scale ( $1=$ no problem to $5=$ very serious) measuring the extent to which they have experienced particular symptoms in the past 7 days. The SCL-90$\mathrm{R}$ consists of nine symptom scales (somatization, obsessive-compulsive, interpersonal sensitivity, depression, anxiety, hostility, phobic anxiety, paranoid ideation, psychoticism) and three global indices [the Global Severity Index (GSI), the Positive Symptom Distress Index (PSDI), and the Positive Symptom Total (PST)]. Higher scores on the SCL-90-R indicate greater psychological distress. The internal consistency coefficient alphas for the nine symptom dimensions ranged from 0.77 for psychoticism, to 0.90 for depression.

This scale was included to study the validity of the YSQ-S3 based on their relationships to symptoms of Axis I disorders such as depression and anxiety. The cognitive content-specificity theory states that each disorder could be characterized by a cognitive content, possibly an EMS in this study, that is specific to that disorder. We used the Korean version of the SCL-90-R, ${ }^{22}$ and only four general symptoms scales (somatization, interpersonal sensitivity, depression, and anxiety) were included in the analysis considering the fact that our subjects are healthy graduate students and multiple correlations may cause confusion to interpret the result.

\section{Modified Experiences in Close Relationships}

The Modified Experiences in Close Relationships (ECR-M36) scale, a modified version of the original 36-item ECR, was designed in 2008 to assess attachment to significant others among medically ill, older individuals. ${ }^{23}$ Each question is scored on a seven-point Likert scale. Odd-numbered questions relate to the avoidance dimension $(\alpha=0.88)$ and even-numbered questions relate to the anxiety dimension $(\alpha=0.91)$. Higher scores indicate more attachment avoidance or attachment anxiety. We included this scale because the theoretical roots of schema theory firmly embedded in attachment theory. The Korean version of the ECR-M36 has good psychometric properties and internal reliability ( $\alpha=0.87$ for all items; $\alpha=0.85$ for anxiety; $\alpha=0.82$ for avoidance). ${ }^{24}$

\section{Beck Depression Inventory}

Current levels of depression were measured with the Korean version of the Beck Depression Inventory (BDI), ${ }^{25}$ a 21 -item scale that targets the cognitive, behavioral, affective, and somatic components of depression. The measure was initially designed to be administered by clinicians, but it is now used primarily as a self-report measure. Each of the 21 items asks respondents to select which of four statements most accurately reflects the intensity of a given symptom during the past week. ${ }^{26}$

\section{Statistical analyses}

We used the Kolmogorov-Smirnov test as the goodness-offit index (GFI) to assess the normality of the distribution of individual schema scores. The internal consistency of all 90 items, as well as of the five items in each schema, was estimated using Cronbach's alpha. Test-retest reliability was assessed using Pearson's correlation coefficients. To assess the concurrent validity of the instrument, correlations between the YSQ-S3 subscales and four of the SCL-90-R subscales, two of the attachment domains of the ECR-M36, and BDI scores were analyzed. Additionally, multiple regression analysis was employed to investigate the extent to which each of the 18 schemas predicted the level of depression and anxiety. SPSS software (version 13; SPSS, Inc., Chicago, IL, USA) was used to perform all analyses. A Bonferroni correction was applied to control the family-wise error rate $(0.05 / 18=0.0028)$.

To test whether our YSQ data fitted an 18-factor structure, ${ }^{15}$ we conducted confirmatory factor analysis (CFA) with the LISREL 8.80 software (Scientific Software International, Inc., Lincolnwood, IL, USA). The maximum likelihood (ML) estimation approach was used to estimate the parameters. Traditionally, chi-squared tests are used in two ways. First, a non-significant chisquare statistic suggests that the model does not deviate from the data. Second, when the chi-square statistic is significant but less than twice the degrees of freedom, the model is considered to be a good representation of the data. However, chi-square values are highly sensitive to sample size and tend to overestimate the badness of a model fit. Thus, the comparative fit in$\operatorname{dex}(\mathrm{CFI})$ and the root mean square error of approximation (RMSEA) were calculated in addition to the more traditional chisquare and GFI values. As a general rule, GFI values $>0.85$, CFI values $>0.90$, and a RMSEA $\leq 0.08$ are considered satisfactory, with CFI values $>0.95$ indicating excellent model fit. Among these fit indices, CFI seems to be the best and most valid because it has a minimal sampling variability and a negligible downward bias relative to the other indices.

\section{RESULTS}

\section{Descriptive statistics}

Mean scores for the 18 individual schemas are presented in Table 1. Mean schema scores were similar to (albeit lower than) 
Table 1. Descriptive statistics for the subscales of $Y S Q-S 3(N=542)$

\begin{tabular}{|c|c|c|c|c|c|c|}
\hline \multirow{2}{*}{ Schema } & \multicolumn{4}{|c|}{ Schema score } & \multicolumn{2}{|c|}{ Distribution } \\
\hline & Mean & SD & Min & Max & Skewness & Kurtosis \\
\hline 1. Emotional deprivation & 7.2 & 3.5 & 5 & 29 & 2.5 & 8.2 \\
\hline 2. Abandonment & 9.5 & 4.0 & 5 & 27 & 1.1 & 1.0 \\
\hline 3. Mistrust/abuse & 7.4 & 3.2 & 5 & 27 & 2.0 & 5.3 \\
\hline 4. Social Isolation/alienation & 8.2 & 3.7 & 5 & 30 & 1.8 & 4.3 \\
\hline 5. Defectiveness/shame & 6.9 & 3.2 & 5 & 29 & 3.1 & 13.4 \\
\hline 6. Failure & 7.5 & 3.5 & 5 & 28 & 2.5 & 8.4 \\
\hline 7. Dependence/incompetence & 8.0 & 3.2 & 5 & 26 & 1.7 & 4.5 \\
\hline 8. Vulnerability to harm or illness & 8.2 & 3.4 & 5 & 29 & 1.5 & 3.4 \\
\hline 9. Enmeshment/undeveloped self & 8.9 & 3.6 & 5 & 22 & 1.1 & 0.9 \\
\hline 10. Subjugation & 9.3 & 3.3 & 5 & 25 & 1.4 & 2.8 \\
\hline 11. Self-sacrifice & 12.2 & 3.6 & 5 & 26 & 0.5 & 0.7 \\
\hline 12. Emotional inhibition & 10.1 & 4.2 & 5 & 29 & 1.0 & 1.2 \\
\hline 13. Unrelenting standards/hypercriticalness & 13.1 & 4.3 & 5 & 29 & 0.6 & 0.5 \\
\hline 14. Entitlement/grandiosity & 12.8 & 3.6 & 5 & 29 & 0.4 & 0.5 \\
\hline 15. Insufficient self-control/self-discipline & 10.2 & 3.4 & 5 & 23 & 0.8 & 0.9 \\
\hline 16. Approval seeking/recognition seeking & 14.9 & 4.9 & 5 & 30 & 0.4 & -0.2 \\
\hline 17. Negativity/pessimism & 10.2 & 3.9 & 5 & 30 & 0.9 & 1.7 \\
\hline 18. Punitiveness & 11.5 & 3.5 & 5 & 29 & 0.7 & 1.9 \\
\hline
\end{tabular}

Standard error of skewness $=0.11$, standard error of kurtosis=0.21. SD: standard deviation, YSQ-S3: Young Schema Questionniare-Short form version 3

those for the previous version of the YSQ-S2 with a South Korean sample. ${ }^{11}$ The Kolmogorov-Smirnov GFI test for a normal distribution indicated a positively skewed distribution for all schemas (D values: $0.08-2.77$, all $\mathrm{df}=542$, all $\mathrm{p}<0.001$ ).

\section{Reliability}

The internal consistency of the 90-item Korean YSQ-S3, measured by the Cronbach's alpha coefficient, was 0.97 . With the following exceptions, the internal consistency for each schema was higher than the generally accepted value of 0.70: 0.69 for insufficient self-control and punitiveness, 0.66 for self-sacrifice, and 0.59 for entitlement/grandiosity (Table 2). However, Kline noted that values below even 0.70 can be expected when dealing with psychological constructs due to the diversity of the constructs being measured. ${ }^{27}$

In terms of the corrected item-total correlation within each schema, all 90 items showed correlations $>0.25$ with the total score for each schema. However, items 45 (enmeshment/undeveloped self), 46 (subjugation), 69 (insufficient self-control), 86 (entitlement), and 90 (punitiveness) showed relatively low itemtotal correlations $(<0.30)$.

Among the 308 participants who completed the YSQ-S3 before and after a 2-year interval, the Pearson's r correlation coefficient for test-retest reliability ranged from 0.46 (entitlement/ grandiosity) to 0.65 (abandonment) (all $\mathrm{p}<0.001)$ (Table 3).

\section{Concurrent validity}

Correlations between the YSQ-S3 and the SCL-90-R, BDI, and ECR-M36 are presented in Table 4. In general, every schema was positively correlated with almost all psychological measures.

In terms of the SCL-90-R subscales, somatization was significantly correlated with the schemas, albeit relatively more weakly than were the other symptom subscales. Interpersonal sensitivity showed the strongest correlation with social isolation/alienation $(\mathrm{r}=0.55, \mathrm{p}<0.001)$, followed by mistrust/abuse $(\mathrm{r}=0.54, \mathrm{p}<0.001)$. Depression showed the strongest correlation with social isolation/alienation $(\mathrm{r}=0.57, \mathrm{p}<0.001)$, followed by failure $(\mathrm{r}=0.52, \mathrm{p}<0.001)$, mistrust/abuse $(\mathrm{r}=0.52, \mathrm{p}<0.001)$, and defectiveness/shame $(\mathrm{r}=0.50, \mathrm{p}<0.001)$. Similar relationships were found with the BDI. Anxiety showed the highest correlation with mistrust/abuse $(\mathrm{r}=0.47, \mathrm{p}<0.001)$, followed by social isolation/alienation $(\mathrm{r}=0.46, \mathrm{p}<0.001)$ and vulnerability to harm or illness $(\mathrm{r}=0.440, \mathrm{p}<0.001)$.

In the context of attachment to others, the anxiety domain showed the strongest correlation with the emotional deprivation schema $(\mathrm{r}=0.49, \mathrm{p}<0.001)$, whereas the avoidance domain showed the strongest correlation with the abandonment sche$\mathrm{ma}(\mathrm{r}=0.68, \mathrm{p}<0.001)$.

Multiple regression analysis was performed using the simultaneous entry method (Table 5). The 18 schemas accounted for 
Table 2. Split-half reliability for the subscales of YSQ-S3 $(N=542)$

\begin{tabular}{lc}
\hline \multicolumn{1}{c}{ Schema } & Cronbach's alpha \\
\hline 1. Emotional deprivation & 0.86 \\
2. Abandonment & 0.79 \\
3. Mistrust/abuse & 0.88 \\
4. Social isolation/alienation & 0.82 \\
5. Defectiveness/shame & 0.89 \\
6. Failure & 0.90 \\
7. Dependence/incompetence & 0.81 \\
8. Vulnerability to harm or illness & 0.75 \\
9. Enmeshment/undeveloped self & 0.72 \\
10. Subjugation & 0.70 \\
11. Self-sacrifice & 0.66 \\
12. Emotional inhibition & 0.79 \\
13. Unrelenting standards/hypercriticalness & 0.74 \\
14. Entitlement/grandiosity & 0.59 \\
15. Insufficient self-control/self-discipline & 0.69 \\
16. Approval seeking/recognition seeking & 0.82 \\
17. Negativity/pessimism & 0.75 \\
18. Punitiveness & 0.69 \\
\hline YQ-S3: Young Schema Questionniare-Short form &
\end{tabular}

YSQ-S3: Young Schema Questionniare-Short form version 3

a total of $41 \%$ (39\% adjusted) of the variance in BDI scores ( $\mathrm{F}=$ $20.46, \mathrm{p}<0.001$ ) and $31 \%$ (29\% adjusted) of the variance in anxiety scores $(\mathrm{F}=13.08, \mathrm{p}<0.001)$ (Table 5$)$.

\section{Confirmatory factor analysis}

The fit indices and ML estimates for an 18-factor model are presented in Table 6. The CFA for the 18-factor structure originally proposed by Young et al. ${ }^{7}$ showed that most, but not all, goodness-of-fit statistics were indicative of a satisfactory fit. Indeed, the chi-square value was significant $\left(\chi_{3762}^{2}=4454.46, p<\right.$ 0.001 ) but lower than the desired 2:1 chi-square:df ratio. The other fit indices reached conventional levels of adequacy: RMSEA $=0.03,90 \%$ confidence interval for RMSEA $=(0.027,0.034)$, $\mathrm{p}$-value for test of close fit $(\mathrm{RMSEA}<0.05)=1.00$, and $\mathrm{CFI}=1.00$. However, the GFI value was 0.67 , which is below the satisfactory value of 0.85 .

\section{DISCUSSION}

The present study examined the reliability, validity, and factor structure of the Korean version of the YSQ-S3. The Korean version of the YSQ-S3 was found to be reliable and stable. The internal consistency of all 90 items was 0.97 , and that of individual schemas was generally higher than the accepted value of 0.70 . These findings are consistent with versions in other languages such as Arabic $(0.71-0.88 ; 0.74-0.86),{ }^{28,29}$ Romanian
Table 3. Pearson's correlation between the test and re-test for the subscales of YSQ-S3 ( $N=308)$

\begin{tabular}{lc}
\hline \multicolumn{1}{c}{ Schema } & $\begin{array}{c}\text { Correlation } \\
\text { coefficient }\end{array}$ \\
\hline 1. Emotional deprivation & 0.47 \\
2. Abandonment & 0.65 \\
3. Mistrust/abuse & 0.58 \\
4. Social isolation/alienation & 0.64 \\
5. Defectiveness/shame & 0.61 \\
6. Failure & 0.58 \\
7. Dependence/incompetence & 0.64 \\
8. Vulnerability to harm or illness & 0.54 \\
9. Enmeshment/undeveloped self & 0.55 \\
10. Subjugation & 0.60 \\
11. Self-sacrifice & 0.55 \\
12. Emotional inhibition & 0.57 \\
13. Unrelenting standards/hypercriticalness & 0.47 \\
14. Entitlement/grandiosity & 0.46 \\
15. Insufficient self-control/self-discipline & 0.52 \\
16. Approval seeking/recognition seeking & 0.60 \\
17. Negativity/pessimism & 0.57 \\
18. Punitiveness & 0.51 \\
\hline All p &
\end{tabular}

All $\mathrm{p}<0.001$. YSQ-S3: Young Schema Questionniare-Short form version 3

$(0.68-0.96),{ }^{30}$ and Turkish $(0.63-0.80)^{31}$ as well as with the previous Korean version of the YSQ-S2 (0.72-0.90 for 13 schemas). ${ }^{11}$ Although the schemas with low internal consistency varied across studies, entitlement/grandiosity showed the lowest internal consistency (0.59) in this study. In fact, item-correlations for these five items were all $<0.40$, and that for item 86 was only 0.25 . One reason may be that the positive connotation of "value" and "contribution," which appear in item 86 ("I feel that what I have to offer is of greater value than the contributions of others"), may make participants, especially medical school students, respond more positively to this item than to other items.

In terms of test-retest reliability, the correlation coefficients for 18 schemas before and after the 2-year interval were between 0.46 and 0.64 . Considering the long interval, the correlations between the YSQ-S3 at baseline and follow-up were relatively strong. Consistent with the reports of Riso et al. ${ }^{32}$ ( $r h o=0.55-$ 0.85 ) and Wang et al. ${ }^{33}$ ( $r h o=0.42-0.73$ ), these findings may rather support the long-term stability of EMSs.

The correlations between the YSQ-S3 and the SCL-90R, BDI, and ECR-M36 further demonstrate the concurrent validity of the YSQ-S3. Consistent with the previous version, the YSQS2, ${ }_{11}$ and versions of the YSQ-S3 in other languages, ${ }^{28-31}$ every schema measured by the Korean version of the YSQ-S3 showed 
Table 4. Pearson's correlations between the YSQ-S3, SCL-90R, BDI, and ECR-M36

\begin{tabular}{|c|c|c|c|c|c|c|c|}
\hline \multirow[b]{2}{*}{ Schema } & \multicolumn{4}{|c|}{ SCL-90R } & \multirow[b]{2}{*}{ BDI } & \multicolumn{2}{|c|}{ ECR-M36 } \\
\hline & Somatization & $\begin{array}{c}\text { Interpersonal } \\
\text { sensitivity }\end{array}$ & Depression & Anxiety & & $\begin{array}{l}\text { Attachment } \\
\text { anxiety }\end{array}$ & $\begin{array}{c}\text { Attachment } \\
\text { avoidance }\end{array}$ \\
\hline 1. Emotional deprivation & $0.26^{* *}$ & $0.39^{* *}$ & $0.41^{* *}$ & $0.33^{* *}$ & $0.41^{* *}$ & $0.49^{* *}$ & $0.25^{* *}$ \\
\hline 2. Abandonment & $0.32^{* *}$ & $0.46^{* *}$ & $0.45^{* *}$ & $0.42^{* *}$ & $0.45^{* *}$ & 0.12 & $0.68^{* *}$ \\
\hline 3. Mistrust/abuse & $0.34^{* *}$ & $0.54^{* *}$ & $0.52^{* *}$ & $0.47^{* *}$ & $0.54^{* *}$ & $0.43^{* *}$ & $0.47^{* *}$ \\
\hline 4. Social Isolation/alienation & $0.33^{* *}$ & $0.55^{* *}$ & $0.57^{* *}$ & $0.46^{* *}$ & $0.52^{* *}$ & $0.43^{* *}$ & $0.53^{* *}$ \\
\hline 5. Defectiveness/shame & $0.30^{* *}$ & $0.48^{* *}$ & $0.50^{* *}$ & $0.41^{* *}$ & $0.53^{* *}$ & $0.40^{* *}$ & $0.38^{* *}$ \\
\hline 6. Failure & $0.26^{* *}$ & $0.46^{* *}$ & $0.52^{* *}$ & $0.42^{* *}$ & $0.56^{* *}$ & $0.22^{*}$ & $0.36^{* *}$ \\
\hline 7. Dependence/incompetence & $0.29^{* *}$ & $0.45^{* *}$ & $0.50^{* *}$ & $0.42^{* *}$ & $0.56^{* *}$ & 0.19 & $0.47^{* *}$ \\
\hline 8. Vulnerability to harm or illness & $0.34^{* *}$ & $0.49^{* *}$ & $0.48^{* *}$ & $0.44^{* *}$ & $0.48^{* *}$ & $0.29^{* *}$ & $0.47^{* *}$ \\
\hline 9. Enmeshment/undeveloped self & $0.31^{* *}$ & $0.40^{* *}$ & $0.39^{* *}$ & $0.34^{* *}$ & $0.41^{* *}$ & 0.18 & $0.47^{* *}$ \\
\hline 10. Subjugation & $0.27^{* *}$ & $0.44^{* *}$ & $0.46^{* *}$ & $0.39^{* *}$ & $0.48^{* *}$ & $0.25^{* *}$ & $0.54^{* *}$ \\
\hline 11. Self-sacrifice & $0.20^{* *}$ & $0.26^{* *}$ & $0.27^{* *}$ & $0.24^{* *}$ & $0.27^{* *}$ & -0.01 & $0.38^{* *}$ \\
\hline 12. Emotional inhibition & $0.28^{* *}$ & $0.45^{* *}$ & $0.43^{* *}$ & $0.36^{* *}$ & $0.42^{* *}$ & $0.40^{* *}$ & $0.43^{* *}$ \\
\hline 13. Unrelenting standards/hypercriticalness & $0.17^{* *}$ & $0.34^{* *}$ & $0.30^{* *}$ & $0.30^{* *}$ & $0.30^{* *}$ & 0.15 & $0.35^{* *}$ \\
\hline 14. Entitlement/grandiosity & $0.27^{* *}$ & $0.42^{* *}$ & $0.37^{* *}$ & $0.32^{* *}$ & $0.32^{* *}$ & 0.06 & $0.39 * *$ \\
\hline 15. Insufficient self-control/self-discipline & $0.29 * *$ & $0.43^{* *}$ & $0.39^{* *}$ & $0.33^{* *}$ & $0.38^{* *}$ & 0.15 & $0.42^{* *}$ \\
\hline 16. Approval seeking/recognition seeking & $0.25^{* *}$ & $0.44^{* *}$ & $0.39^{* *}$ & $0.36^{* *}$ & $0.36^{* *}$ & 0.01 & $0.55^{* *}$ \\
\hline 17. Negativity/pessimism & $0.30^{* *}$ & $0.47^{* *}$ & $0.44^{* *}$ & $0.41^{* *}$ & $0.42^{* *}$ & $0.35^{* *}$ & $0.52^{* *}$ \\
\hline 18. Punitiveness & $0.24^{* *}$ & $0.32 * *$ & $0.28^{* *}$ & $0.29^{* *}$ & $0.28^{* *}$ & 0.14 & $0.32^{* *}$ \\
\hline
\end{tabular}

${ }^{*} \mathrm{p}<0.001,{ }^{* *} \mathrm{p}<0.0001 . \mathrm{N}=542$ for SCL-90-R and BDI; N=217 for ECR-M36. YSQ-S3: Young Schema Questionnaire-short form 3, SCL-90-R: Symptom checklist-90-R, BDI: Beck Depression Inventory, ECR-M36: Modified experiences in close relationships

Table 5. Multiple regression for depression and anxiety

\begin{tabular}{|c|c|c|c|c|c|c|c|c|c|c|}
\hline \multirow{2}{*}{ Schema } & \multicolumn{5}{|c|}{ Regression with depression score ${ }^{*+\ddagger}$} & \multicolumn{5}{|c|}{ Regression with anxiety scoresిlा } \\
\hline & B & SE B & $\beta$ & $\mathrm{t}$ & $\mathrm{p}$ & B & SE B & $\beta$ & $\mathrm{t}$ & $\mathrm{p}$ \\
\hline 1. Emotional deprivation & -0.10 & 0.09 & -0.06 & -1.11 & 0.27 & -0.14 & 0.10 & -0.09 & -1.40 & 0.16 \\
\hline 2. Abandonment & 0.01 & 0.07 & 0.01 & 0.17 & 0.86 & 0.11 & 0.08 & 0.08 & 1.40 & 0.16 \\
\hline 3. Mistrust/abuse & 0.26 & 0.10 & 0.16 & 2.68 & 0.01 & 0.28 & 0.11 & 0.16 & 2.47 & 0.01 \\
\hline 4. Social isolation/alienation & 0.13 & 0.10 & 0.09 & 1.35 & 0.18 & 0.27 & 0.11 & 0.17 & 2.38 & 0.02 \\
\hline 5. Defectiveness/shame & 0.10 & 0.12 & 0.06 & 0.84 & 0.40 & -0.10 & 0.14 & -0.05 & -0.69 & 0.49 \\
\hline 6. Failure & 0.33 & 0.09 & 0.22 & 3.81 & $<0.001$ & 0.21 & 0.10 & 0.13 & 2.02 & 0.04 \\
\hline 7. Dependence/incompetence & 0.26 & 0.10 & 0.16 & 2.58 & 0.01 & 0.10 & 0.12 & 0.06 & 0.87 & 0.38 \\
\hline 8. Vulnerability to harm or illness & 0.04 & 0.10 & 0.03 & 0.44 & 0.66 & 0.16 & 0.11 & 0.09 & 1.39 & 0.16 \\
\hline 9. Enmeshment/undeveloped self & 0.06 & 0.07 & 0.04 & 0.89 & 0.37 & 0.02 & 0.08 & 0.01 & 0.27 & 0.79 \\
\hline 10. Subjugation & -0.09 & 0.11 & -0.05 & -0.81 & 0.42 & -0.17 & 0.13 & -0.10 & -1.36 & 0.17 \\
\hline 11. Self-sacrifice & 0.03 & 0.07 & 0.02 & 0.45 & 0.66 & 0.00 & 0.08 & 0.00 & -0.04 & 0.97 \\
\hline 12. Emotional inhibition & 0.03 & 0.06 & 0.02 & 0.44 & 0.66 & 0.01 & 0.07 & 0.01 & 0.14 & 0.89 \\
\hline 13. Unrelenting standards/hypercriticalness & 0.12 & 0.06 & 0.10 & 2.13 & 0.03 & 0.12 & 0.07 & 0.09 & 1.75 & 0.08 \\
\hline 14. Entitlement/grandiosity & -0.01 & 0.08 & -0.01 & -0.13 & 0.90 & 0.01 & 0.09 & 0.01 & 0.10 & 0.92 \\
\hline 15. Insufficient self-control/self-discipline & 0.02 & 0.08 & 0.01 & 0.25 & 0.80 & 0.00 & 0.09 & 0.00 & 0.02 & 0.98 \\
\hline 16. Approval seeking/recognition seeking & 0.09 & 0.05 & 0.08 & 1.81 & 0.07 & 0.13 & 0.06 & 0.11 & 2.21 & 0.03 \\
\hline 17. Negativity/pessimism & 0.01 & 0.08 & 0.00 & 0.07 & 0.94 & 0.08 & 0.09 & 0.05 & 0.88 & 0.38 \\
\hline 18. Punitiveness & -0.13 & 0.07 & -0.09 & -1.86 & 0.06 & -0.02 & 0.08 & -0.02 & -0.30 & 0.76 \\
\hline
\end{tabular}

*dependent variable: Beck depression score, ${ }^{+} \mathrm{R}^{2}$ : $0.41, \mathrm{~F}: 20.46, \mathrm{p}<0.001$, ${ }^{\ddagger}$ constant: $\mathrm{B}(\mathrm{SE})=-3.41(0.83)$, $\mathrm{t}=-4.12$, §dependent variable: anxiety

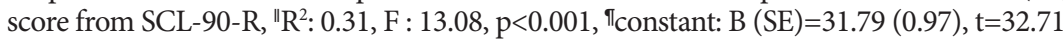


Table 6. Maximum likelihood estimates for a 18-schema structure

\begin{tabular}{|c|c|c|c|c|c|c|c|c|c|c|c|c|c|c|c|c|c|c|}
\hline & $\mathrm{S} 1$ & S2 & S3 & S4 & S5 & S6 & S7 & S8 & S9 & $\mathrm{S} 10$ & S11 & $\mathrm{S} 12$ & S13 & S14 & $\mathrm{S} 15$ & S16 & S17 & S18 \\
\hline Item 1 & 0.68 & & & & & & & & & & & & & & & & & \\
\hline Item 19 & 0.82 & & & & & & & & & & & & & & & & & \\
\hline Item 37 & 0.73 & & & & & & & & & & & & & & & & & \\
\hline Item 55 & 0.80 & & & & & & & & & & & & & & & & & \\
\hline Item 73 & 0.72 & & & & & & & & & & & & & & & & & \\
\hline Item 2 & & 0.74 & & & & & & & & & & & & & & & & \\
\hline Item 20 & & 0.59 & & & & & & & & & & & & & & & & \\
\hline Item 38 & & 0.80 & & & & & & & & & & & & & & & & \\
\hline Item 56 & & 0.56 & & & & & & & & & & & & & & & & \\
\hline Item 74 & & 0.64 & & & & & & & & & & & & & & & & \\
\hline Item 3 & & & 0.68 & & & & & & & & & & & & & & & \\
\hline Item 21 & & & 0.72 & & & & & & & & & & & & & & & \\
\hline Item 39 & & & 0.78 & & & & & & & & & & & & & & & \\
\hline Item 57 & & & 0.80 & & & & & & & & & & & & & & & \\
\hline Item 75 & & & 0.78 & & & & & & & & & & & & & & & \\
\hline Item 4 & & & & 0.69 & & & & & & & & & & & & & & \\
\hline Item 22 & & & & 0.48 & & & & & & & & & & & & & & \\
\hline Item 40 & & & & 0.80 & & & & & & & & & & & & & & \\
\hline Item 58 & & & & 0.82 & & & & & & & & & & & & & & \\
\hline Item 76 & & & & 0.76 & & & & & & & & & & & & & & \\
\hline Item 5 & & & & & 0.67 & & & & & & & & & & & & & \\
\hline Item 23 & & & & & 0.71 & & & & & & & & & & & & & \\
\hline Item 41 & & & & & 0.76 & & & & & & & & & & & & & \\
\hline Item 59 & & & & & 0.78 & & & & & & & & & & & & & \\
\hline Item 77 & & & & & 0.78 & & & & & & & & & & & & & \\
\hline Item 6 & & & & & & 0.74 & & & & & & & & & & & & \\
\hline Item 24 & & & & & & 0.72 & & & & & & & & & & & & \\
\hline Item 42 & & & & & & 0.70 & & & & & & & & & & & & \\
\hline Item 60 & & & & & & 0.81 & & & & & & & & & & & & \\
\hline Item 78 & & & & & & 0.77 & & & & & & & & & & & & \\
\hline Item 7 & & & & & & & 0.75 & & & & & & & & & & & \\
\hline Item 25 & & & & & & & 0.64 & & & & & & & & & & & \\
\hline Item 43 & & & & & & & 0.52 & & & & & & & & & & & \\
\hline Item 61 & & & & & & & 0.74 & & & & & & & & & & & \\
\hline Item 79 & & & & & & & 0.79 & & & & & & & & & & & \\
\hline Item 8 & & & & & & & & 0.71 & & & & & & & & & & \\
\hline Item 26 & & & & & & & & 0.47 & & & & & & & & & & \\
\hline Item 44 & & & & & & & & 0.77 & & & & & & & & & & \\
\hline Item 62 & & & & & & & & 0.68 & & & & & & & & & & \\
\hline Item 80 & & & & & & & & 0.58 & & & & & & & & & & \\
\hline Item 9 & & & & & & & & & 0.56 & & & & & & & & & \\
\hline Item 27 & & & & & & & & & 0.66 & & & & & & & & & \\
\hline
\end{tabular}


Development of the Korean YSQ-S3

Table 6. Maximum likelihood estimates for a 18-schema structure (continued)

\begin{tabular}{|c|c|c|c|c|c|c|c|c|c|c|c|c|c|c|c|c|c|c|}
\hline & $\mathrm{S} 1$ & $\mathrm{~S} 2$ & S3 & S4 & S5 & S6 & S7 & S8 & S9 & $\mathrm{S} 10$ & $\mathrm{~S} 11$ & $\mathrm{~S} 12$ & $\mathrm{~S} 13$ & $\mathrm{~S} 14$ & S15 & S16 & $\mathrm{S} 17$ & S18 \\
\hline Item 45 & & & & & & & & & 0.38 & & & & & & & & & \\
\hline Item 63 & & & & & & & & & 0.73 & & & & & & & & & \\
\hline Item 81 & & & & & & & & & 0.79 & & & & & & & & & \\
\hline Item 10 & & & & & & & & & & 0.62 & & & & & & & & \\
\hline Item 28 & & & & & & & & & & 0.64 & & & & & & & & \\
\hline Item 46 & & & & & & & & & & 0.31 & & & & & & & & \\
\hline Item 64 & & & & & & & & & & 0.68 & & & & & & & & \\
\hline Item 82 & & & & & & & & & & 0.71 & & & & & & & & \\
\hline Item 11 & & & & & & & & & & & 0.30 & & & & & & & \\
\hline Item 29 & & & & & & & & & & & 0.42 & & & & & & & \\
\hline Item 47 & & & & & & & & & & & 0.63 & & & & & & & \\
\hline Item 65 & & & & & & & & & & & 0.46 & & & & & & & \\
\hline Item 83 & & & & & & & & & & & 0.77 & & & & & & & \\
\hline Item 12 & & & & & & & & & & & & 0.60 & & & & & & \\
\hline Item 30 & & & & & & & & & & & & 0.57 & & & & & & \\
\hline Item 48 & & & & & & & & & & & & 0.70 & & & & & & \\
\hline Item 66 & & & & & & & & & & & & 0.69 & & & & & & \\
\hline Item 84 & & & & & & & & & & & & 0.77 & & & & & & \\
\hline Item 13 & & & & & & & & & & & & & 0.55 & & & & & \\
\hline Item 31 & & & & & & & & & & & & & 0.41 & & & & & \\
\hline Item 49 & & & & & & & & & & & & & 0.60 & & & & & \\
\hline Item 67 & & & & & & & & & & & & & 0.69 & & & & & \\
\hline Item 85 & & & & & & & & & & & & & 0.61 & & & & & \\
\hline Item 14 & & & & & & & & & & & & & & 0.66 & & & & \\
\hline Item 32 & & & & & & & & & & & & & & 0.57 & & & & \\
\hline Item 50 & & & & & & & & & & & & & & 0.44 & & & & \\
\hline Item 68 & & & & & & & & & & & & & & 0.51 & & & & \\
\hline Item 86 & & & & & & & & & & & & & & 0.26 & & & & \\
\hline Item 15 & & & & & & & & & & & & & & & 0.68 & & & \\
\hline Item 33 & & & & & & & & & & & & & & & 0.62 & & & \\
\hline Item 51 & & & & & & & & & & & & & & & 0.63 & & & \\
\hline Item 69 & & & & & & & & & & & & & & & 0.37 & & & \\
\hline Item 87 & & & & & & & & & & & & & & & 0.62 & & & \\
\hline Item 16 & & & & & & & & & & & & & & & & 0.54 & & \\
\hline Item 34 & & & & & & & & & & & & & & & & 0.71 & & \\
\hline Item 52 & & & & & & & & & & & & & & & & 0.79 & & \\
\hline Item 70 & & & & & & & & & & & & & & & & 0.67 & & \\
\hline Item 88 & & & & & & & & & & & & & & & & 0.71 & & \\
\hline Item 17 & & & & & & & & & & & & & & & & & 0.61 & \\
\hline Item 35 & & & & & & & & & & & & & & & & & 0.61 & \\
\hline Item 53 & & & & & & & & & & & & & & & & & 0.57 & \\
\hline Item 71 & & & & & & & & & & & & & & & & & 0.62 & \\
\hline
\end{tabular}


Table 6. Maximum likelihood estimates for a 18-schema structure (continued)

\begin{tabular}{|c|c|c|c|c|c|c|c|c|c|c|c|c|c|c|c|c|c|c|}
\hline & S1 & S2 & S3 & $\mathrm{S} 4$ & S5 & S6 & S7 & S8 & S9 & $\mathrm{S} 10$ & S11 & $\mathrm{S} 12$ & $\mathrm{~S} 13$ & S14 & S15 & S16 & $\mathrm{S} 17$ & S18 \\
\hline Item 89 & & & & & & & & & & & & & & & & & 0.74 & \\
\hline Item 18 & & & & & & & & & & & & & & & & & & 0.50 \\
\hline Item 36 & & & & & & & & & & & & & & & & & & 0.63 \\
\hline Item 54 & & & & & & & & & & & & & & & & & & 0.48 \\
\hline Item 72 & & & & & & & & & & & & & & & & & & 0.62 \\
\hline Item 90 & & & & & & & & & & & & & & & & & & 0.43 \\
\hline
\end{tabular}

All parameters significant at $\mathrm{p}<0.05$; Estimates over 0.4 are shown in bold. $\chi^{2}(3762)=4454.46(\mathrm{p}<0.001), \mathrm{CFI}=1.00, \mathrm{RMSEA}=0.03$, GFI $=0.67$. $\mathrm{S} 1$ : Emotional deprivation, S2: Abandonment, S3: Mistrust/Abuse, S4: Social Isolation/Alienation, S5: Defectiveness/Shame, S6: Failure, S7: Dependence/Incompetence, S8: Vulnerability to Harm or Illness, S9: Enmeshment/Undeveloped Self, S10: Subjugation, S11: Self-Sacrifice, S12: Emotional Inhibition, S13: Unrelenting Standards/Hypercriticalness, S14: Entitlement/Grandiosity, S15: Insufficient Self-Control/Self-Discipline, S16: Approval Seeking/Recognition Seeking, S17: Negativity/Pessimism, S18: Punitiveness

statistically significant correlations with measures of the clinical symptoms of depression, anxiety, somatization, and social isolation. Moreover, the schemas accounted for $41 \%$ and $31 \%$ of the total variance in depression and anxiety symptoms, respectively, in this study. In fact, the schemas are well-known predictors of depression and anxiety, accounting for approximately $40-50 \%$ of the variance of depressive and anxiety symptoms. ${ }^{5,16}$ In this sense, some authors have already proposed that schema theory and therapy should be applied to treat mood and anxiety disorders. ${ }^{5}$

This study also revealed that the YSQ-S3 was closely related to two dimensions of adult attachment: attachment anxiety, defined as fear of interpersonal rejection or abandonment, and attachment avoidance, defined as fear of dependence and interpersonal intimacy. ${ }^{34}$ In the schema model, secure attachment to others (which includes safety, stability, nurturance, and acceptance) is one of five core emotional needs of human beings. According to this model, childhood emotional development proceeds from attachment to autonomy and individuation. ${ }^{2}$ Young et al. originally designed the first domain, the so-called disconnection and rejection domain, to describe patients with schemas that rendered them unable to form secure, satisfying attachments to others. ${ }^{2}$ In fact, as originally conceived, emotional deprivation and abandonment, which showed the strongest correlations with attachment anxiety and attachment avoidance, respectively, were included in this domain. These findings may support the incorporation of attachment theory into the basic conceptual assumptions of schema theory. However, other schemas that do not belong to the rejection and disconnection domain also showed significant correlations with attachment domains, especially with attachment avoidance. A previous study reported that attachment avoidance and anxiety were significantly associated with all schemas within the disconnection domain, and were associated with a number of EMS in other domains. ${ }^{35}$ We assume that attachment may have an impact on the development of schemas in general.
The CFAs using the ML procedure in LISREL indicated that the hypothesized 18-factor structure of the Korean version of the YSQ-S3 provided an acceptable fit to the data. Several previous studies have tested the factor structure of the YSQ-S3 with mixed results, finding $18-,{ }^{36} 17-,{ }^{28}$ and 14 -factor structures. ${ }^{31}$ These minor discrepancies in the factor structures identified by different studies may be attributable to various causes, including cultural differences, translation problems, and the use of different subject groups. Although the previous Korean version of the YSQ-S2 showed a moderate fit with the data according to the 15-factor model, a 13-factor solution, which excluded the dependence/independence and subjugation schemas, provided a better fit for the data. Unlike the Korean version of the YSQ-S2, our version of the YSQ-S3 showed a good fit with the original factor structure. It is worth noting that our version was translated independently from the earlier version.

The current study has several limitations. First, caution is needed in generalizing our findings because our subjects were graduate medical students. In fact, their mean scores on schemas were generally lower, by 1-2 points, than were those of the undergraduate psychology students examined in previous research regarding the YSQ-S2. However, our subjects may be suitable for validation of this measure because they constituted a highly homogenous and reliable sample. Further research with more representative samples including various age groups is needed. Second, as the YSQ was developed to assess severe and long-lasting characterological problems in clinical subjects, such as patients with personality disorders, additional studies with clinical samples are needed to establish its discriminant validity. Third, though we included the SCL-90R and attachment scale for concurrent validity, the lack of measures regarding core beliefs or personality may limit the interpretation of concurrent validity of the Korean version of the YSQ-S3.

In conclusion, the present study confirmed the reliability, validity, and sound psychometric properties of the Korean version of the YSQ-S3 in healthy medical students. Future research 
with clinical samples is needed to determine its clinical utility.

\section{REFERENCES}

1. Young JE, Klosko JS. Reinventing Your Life. New York: Plume; 1994.

2. Young JE, Klosko JS, Weishaar ME. Schema Therapy: A Practitioner's Guide. New York: Guilford Press; 2003.

3. Bamelis LL, Evers SM, Spinhoven P, Arntz A. Results of a multicenter randomized controlled trial of the clinical effectiveness of schema therapy for personality disorders. Am J Psychiatry 2014;171:305-322.

4. Carter JD, McIntosh VV, Jordan J, Porter RJ, Frampton CM, Joyce PR. Psychotherapy for depression: a randomized clinical trial comparing schema therapy and cognitive behavior therapy. J Affect Disord 2013; 151:500-505.

5. Hawke LD, Provencher MD. Schema theory and schema therapy in mood and anxiety disorders: a review. J Cogn Psychother 2011;25:257276.

6. Sempertegui GA, Karreman A, Arntz A, Bekker MH. Schema therapy for borderline personality disorder: a comprehensive review of its empirical foundations, effectiveness and implementation possibilities. Clin Psychol Rev 2013;33:426-447.

7. Young JE. Cognitive Therapy for Personality Disorders: A Schema-Focused Approach. Sarasota: Professional Resource Exchange; 1990.

8. Young JE, Brown G. Young Schema-Questionnaire, 2nd Edition. In: Young JE, Editor. Cognitive Therapy for Personality Disorders: A Schema-Focused Approach (Revised Ed.). Sarasota: Professional Resource Press/ Professional Resource Exchange, 1994, p.63-76.

9. Young JE. Young Schema Questionnaire-Long gorm 3 (YSQ-L3). New York: Schema Therapy Institute; 2003.

10. Young JE. Young Schema Questionnaire-Short Form 3 (YSQ-S3). New York: Schema Therapy Institute; 2005.

11. Baranoff J, Oei TP, Cho SH, Kwon SM. Factor structure and internal consistency of the Young Schema Questionnaire (Short Form) in Korean and Australian samples. J Affect Disord 2006;93:133-140.

12. Lee CW, Taylor G, Dunn J. Factor structure of the Schema Questionnaire in a large clinical sample. Cogn Ther Res 1999;23:441-451.

13. Schmidt NB, Joiner TE, Young JE, Telch MJ. The schema questionnaire: Investigation of psychometric properties and the hierarchical structure of a measure of maladaptive schemas. Cogn Ther Res 1995;19:295-321.

14. Rijkeboer MM, van den Bergh H, van den Bout J. Stability and discriminative power of the Young Schema-Questionnaire in a Dutch clinical versus non-clinical population. J Behav Ther Exp Psychiatry 2005;36:129144.

15. Welburn KR, Coristine M, Dagg P, Pontefract A, Jordan S. The schema questionnaire-short form: factor analysis and relationship between schemas and symptoms. Cogn Ther Res 2002;26:519-530.

16. Calvete E, Estevez A, de Arroyabe EL, Ruiz P. The Schema Questionnaire-Short Form Structure and relationship with automatic thoughts and symptoms of affective disorders. Eur J Psychol Assess 2005;21:90-99.

17. Cecero JJ, Nelson JD, Gillie JM. Tools and tenets of schema therapy: toward the construct validity of the early maladaptive schema questionnaire-research version (EMSQ-R). Clin Psychol Psychother 2004;11:344357.

18. Stopa L, Thorne P, Waters A, Preston J. Are the short and long forms of the Young Schema Questionnaire comparable and how well does each version predict psychopathology scores? J Cogn Psychother 2001;15:253272.

19. Dobson K. Handbook of Cognitive-Behavioral Therapies, 3rd Edition. New York: Guilford Press; 2009.

20. Cho SH. Factor structure of the Korean version of schema questionnaire. Kor J Couns Psychother 2001;13:177-192.

21. Derogatis LR, Rickels K, Rock AF. The SCL-90 and the MMPI: a step in the validation of a new self-report scale. Br J Psychiatry 1976;128:280289.

22. Kim KI, Kim JH, Won HT. Korean Manual of Symptom Checklist-90Reversion. Seoul: Chungang Aptitude Publishing Co. Ltd.; 1984.

23. Lo C, Walsh A, Mikulincer M, Gagliese L, Zimmermann C, Rodin G. Measuring attachment security in patients with advanced cancer: psychometric properties of a modified and brief Experiences in Close Relationships scale. Psychooncology 2009;18:490-499.

24. Jang B, Rim HD, Woo J. Reliability and validity of the Korean version of the modified adult attachment scale (ECR-M36) for the use in breast cancer patients. Psychiatry Investig Inpress.

25. Lee YH, Song JY. A study of the reliability and the validity of the BDI, SDS, and MMPI-D scales. Korean J Clin Psychol 1991;10:98-113.

26. Beck AT, Ward CH, Mendelson M, Mock J, Erbaugh J. An inventory for measuring depression. Arch Gen Psychiatry 1961;4:561-571.

27. Kline P. The Handbook of Psychological Testing. London: Routledge; 1999.

28. Alfasfos L. The early maladaptive schemas and their correlations with the psychiatric symptoms and the personality accentuations for palestinian students. Hamburg: Hamburg University; 2009.

29. Yousefi N, Shirbagi N. Validating the Young Early Maladaptive Schema Questionnaire (YEMSQ) among Students. Ira J Psychiatry Behav Sci 2010; 4:38-46.

30. Trip S. The Romanian version of young schema questionnaire-short form 3 (YSQ-S3). J Cogn Behav Psychother 2006;5:173-181.

31. Soygut G, Karaosmanoglu A, Cakir Z. [Assessment of early maladaptive schemas: a psychometric study of the Turkish young schema questionnaire-short form-3]. Turk Psikiyatri Derg 2009;20:75-84.

32. Riso LP, Froman SE, Raouf M, Gabel P, Maddux RE, Santorelli NT, et al. The long-term stability of early maladaptive schemas. Cogn Ther Res 2006;30:515-529.

33. Wang CE, Halvorsen M, Eisemann M, Waterloo K. Stability of dysfunctional attitudes and early maladaptive schemas: a 9-year follow-up study of clinically depressed subjects. J Behav Ther Exp Psychiatry 2010;41:389396.

34. Wei M, Russell DW, Mallinckrodt B, Vogel DL. The Experiences in Close Relationship Scale (ECR)-short form: reliability, validity, and factor structure. J Pers Assess 2007;88:187-204.

35. McLean HR, Bailey HN, Lumley MN. The secure base script: associated with early maladaptive schemas related to attachment. Psychol Psychother 2014;87:425-446.

36. Saariaho T, Saariaho A, Karila I, Joukamaa M. The psychometric properties of the Finnish Young Schema Questionnaire in chronic pain patients and a non-clinical sample. J Behav Ther Exp Psychiatry 2009;40: 158-168. 